\title{
A Política da Participação Colaborativa com o Uso das Tecnologias Móveis em EAD
}

\author{
Josie do Amaral Bastos ${ }^{1}$
}

\begin{abstract}
1 Pesquisadora, Programa de Pós-Graduação em Políticas Públicas - Universidade Federal do Maranhão. Av. dos Portugueses, 1966 - Bacanga - São Luís - MA - Brasil. josiebastos@hotmail.com
\end{abstract}

\section{Resumo}

A ascensão do uso dos dispositivos móveis como tablets, smarthphones, netbooks e celulares vem gerando uma transformação na forma de comunicação entre os sujeitos, inseridos neste cenário colaborativo e de aumento da troca de arquivos. $O$ presente artigo é fruto de um projeto de pesquisa que vem se desenvolvendo no Núcleo de Educação a Distância da UFMA (NEAD) por professores, pesquisadores do Núcleo de TV da Assessoria de Comunicação da UFMA e alunos do Departamento de Comunicação da mesma Instituição. O intuito é mostrar a experiência realizada no Núcleo de Produção e Tecnologia Educacional (NPTE) do Instituto Federal de Educação, Ciência e Tecnologia Sul-rio-grandense (IFSUL) para contribuir com uma reflexão sobre o uso adequado do tamanho, das cores e dos contrastes de legendas em materiais audiovisuais direcionados à educação e realizados por alunos e professores do EAD.

Palavras-chave: Comunicação, Tecnologias móveis, Educação a distância. 


\title{
The Policy of Collaborative Participation with the Use of Mobile Technologies in Distance Education
}

\begin{abstract}
The rise in the use of mobile devices such as tablets, smartphones, netbooks, and mobile phones has generated a transformation of communication between subjects entered into this collaborative scenario and increases the exchange of files. This article is the result of a research project that has been developed at the Center for Distance Education UFMA (NEAD) by teachers, researchers of the Center's TV Communication Advisory UFMA, and students of the Department of Communication at the same institution. The aim is to show the experiment conducted at the Center for Educational Technology and Production (NPTE) of the Federal Institute of Education, Science, and Technology of Rio Grande do Sul (IFSUL) and to contribute to a reflection on the proper use of the size and color contrasts of subtitles in audiovisual materials in education and performed by students and teachers of EAD.
\end{abstract}

Keywords: Communication, Mobile technologies, Distance education. 


\section{Introdução}

A cultura da convergência proporcionada pelas tecnologias digitais e da informação representa uma mudança de paradigma nos diferentes setores da mídia e da educação. O conceito utilizado por Jenkins (2009) refere-se a um deslocamento de conteúdos de um campo específico a outros que flui por vários canais em direção a um espaço complexo de interdependência nos sistemas de comunicação. Ela propicia uma série de transformações na sociedade e desafios para o processo de educação a distância, já que aponta para um cenário de fragmentação em que, professores, tutores e alunos se tornam sujeitos participativos no processo de aprendizagem, envolvidos, como aponta Demo (2009), na posição ativa de construção e reconstrução do conhecimento. A ascensão do uso dos dispositivos móveis como tablets, smarthphones, netbooks e celulares vem gerando uma transformação na forma de comunicação entre esses sujeitos, inseridos neste cenário colaborativo e de aumento da troca de arquivos.

O presente artigo é fruto de um projeto de pesquisa que vem se desenvolvendo no Núcleo de Educação a Distancia da UFMA (NEAD) por professores, pesquisadores do Núcleo de TV da Assessoria de Comunicação da UFMA e alunos do Departamento de Comunicação da mesma Instituição. Nos meses de abril e junho, foram realizados cursos de capacitação sobre as etapas de produção de videoaulas (produção, roteirização, apresentação e pós-produção) para professores e técnicos da informação e comunicação do Núcleo, com o objetivo de apresentá-los e provocá-los para o uso potencializado da linguagem audiovisual nas produções de vídeos educacionais disponibilizados no Ambiente Virtual de Aprendizagem (AVA). Além das gravações realizadas em estúdio, com a participação e orientação dos profissionais e técnicos da área da comunicação, observou-se também o interesse por parte de alguns professores, para a produção de vídeos de curta duração, utilizando os smartphones no intuito de atender às demandas urgentes dosalunosque surgem, por exemplo, nos fóruns de discussão.

A política de participação colaborativa com o crescimento do uso dos dispositivos móveis impulsiona o surgimento de iniciativas como essa e que devem ser valorizadas pela política pedagógica da EAD. No entanto, como destacam Schneider e Ribeiro (2013), as produções audiovisuais, fora do contexto profissional, podem apresentar problemas em sua composição, já que são geradas, muitas vezes, com base em 
conhecimentos empíricos, com conteúdos interessantes, mas sem o cuidado necessário com o tratamento estético e sonoro do material (uso inadequado de cores, contrastes e fundo na tela que dificulta a legibilidade textual, enquadramento de planos sem mostrar a peça que se deseja destacar e áudio com aproveitamento apenas do som ambiente contendo ruídos em excesso). Esses elementos, quando utilizados de forma errônea, podem provocar o efeito inverso ao desejado pelo professor e pela política da Instituição que prima pela assimilação do conteúdo didático ofertado em sua totalidade.

O objetivo desse estudo é mostrar a experiência realizada no Núcleo de Produção e Tecnologia Educacional (NPTE) do Instituto Federal de Educação, Ciência e Tecnologia Sul-rio-grandense (IFSUL) ${ }^{1}$ para contribuir com uma reflexão sobre o uso adequado do tamanho, das cores e dos contrastes de legendas em materiais audiovisuais direcionados à educação e realizados por alunos e professores da EAD. As análises apresentadas a partir desse olhar poderão servir de instrumento metodológico para quem deseja aprofundar o conhecimento de alguns aspectos técnicos e estéticos relacionados à produção de vídeos.

\section{O uso de ferramentas eletrônicas como suporte didático da EAD no Brasil}

Moraes e Nogueira (s/d) destacam que no Brasil não há registros precisos sobre a criação da EAD. No entanto, as autoras corroboram com as afirmações de Alves (2009) sobre os primeiros "passos" dessa modalidade de ensino no país. Conforme o

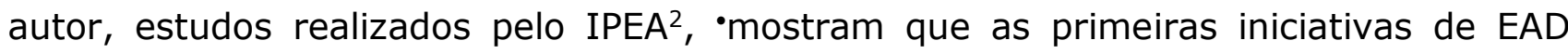
ocorreram no final do século XIX. Nesse período, a educação a distância manteve, como base tecnológica dos conteúdos didáticos, os materiais impressos enviados por correio. Sobre o uso dos equipamentos eletrônicos na EAD, Moraes e Nogueira (s/d) tomam de empréstimos os estudos de Gouvêa e Oliveira (2006) para destacar que a primeira iniciativa brasileira de EAD com a utilização de um recurso eletrônico se deu em 1923, por meio da Rádio Sociedade do Rio de Janeiro. Em 1936, essa rádio tornouse a Rádio Ministério da Educação e Cultura. A partir da década de 1960, surgiram outras iniciativas, por meio do Movimento de Educação de Base (MEB), para promover cursos de alfabetização por meio do sistema radiofônico, e o Projeto Minerva que objetivava, de início, promover o ensino primário até o ginasial pela Rádio MEC. Com a inserção da TV, na década de 1950, começou-se a vislumbrar produções audiovisuais 
para EAD. Na década de 1960, a fundação Roberto Marinho promove a educação supletiva a distância para os antigos primeiros e segundos graus ${ }^{3}$ e, posteriormente, para o desenvolvimento do Telecurso $1^{\circ}$ e $2^{\circ}$ Graus. Conforme os estudos de Passinho (2008), a TVE do Maranhão, criada em 1969, conforme a Lei 3016, foi a primeira no país a utilizar um Sistema de Televisão Educativa no Ensino Fundamental de quinta a oitava séries. Uma iniciativa que se encerra em 2007, após sanção da Medida Provisória 6.689/2008, posteriormente transformada na Lei ${ }^{\circ} 11.652$, de 7 de abril de 2008, que criou a Empresa Brasileira de Comunicação (EBC), denominada de TV Brasil.

Os investimentos em ferramentas tecnológicas em EAD no país, nas décadas de 1950, 1960 e 1970, foram introduzidos, segundo autores como Moraes e Nogueira (s/d) e Montano e Duriguetto (2001), no esforço de acompanhar as mudanças estruturais do país e a uma pressão permanente internacional para a inovação tecnológica. Dessa forma, o reforço na profissionalização e qualificação profissional passa a ser um elemento chave para fomentar o crescimento econômico do Brasil na perspectiva de garantir-Ihe uma vantagem competitiva no mercado internacional.

A grande indústria monopolista, para enfrentar e evitar a concorrência, precisou ingressar numa veloz e permanente corrida tecnológica para se manter tecnologicamente sempre à frente, garantido o diferencial de produtividade frente às concorrentes (...) Com isso, era preciso novamente a participação do Estado, dessa vez para financiar a pesquisa para o desenvolvimento tecnológico e científico a serviço dos interesses do grande capital (...) (MONTANO, DURIGUETTO, 2011, p. 167)"

O computador e a internet (pensada inicialmente por cientistas como uma rede de comunicações), apesar de serem revelados no mundo, respectivamente, nas décadas de 1950 e final de 1960, passam a ser vistos como uma tecnologia educacional, segundo Dornelles (2001), somente por volta de 1977, com a criação dos microcomputadores que permitiu a interligação das redes das máquinas e compartilhamento das informações. Conforme ressalta Sorj (2003), a partir de 1990, a internet $^{4}$ se expande em um momento em que a valorização do conhecimento surge como principal fonte de criação e valor. A EAD se apropria desse recurso para dinamizar ações pedagógicas na plataforma digital com a criação dos ambientes virtuais de aprendizagem incluindo fóruns de discussão, videoaulas, videoconferência, materiais e livros didáticos disponíveis, entre outros. Nessa perspectiva, o uso do youtube também passou a ser mais um instrumento de divulgação de informação pelo 
formato audiovisual por alunos, professores, tutores e pesquisadores de forma colaborativa, podendo ser produzido pelos sujeitos envolvidos no processo de ensinoaprendizagem por meio da utilização de smarthphones e tablets.

\section{A experiência do Núcleo de Produção e Tecnologia Educacional (NPTE) do Instituto Federal de Educação, Ciência e Tecnologia Sul-rio-grandense (IFSUL)}

Para o estudo do Núcleo de Produção e Tecnologia Educacional (NPTE), foram avaliados inicialmente 40 vídeos disponibilizados na plataforma do youtube no contexto da EAD. Desse total, foram selecionados seis que, posteriormente, foram subdivididos em dois grupos: vídeos caseiros e profissionais. A intenção dos pesquisadores foi fazer uma análise do material com base em uma discussão conceitual e metodológica sobre o uso adequado de legendas e enquadramento de planos nas produções audiovisuais veiculadas na web. A revisão bibliográfica que, primordialmente, norteou e fundamentou o trabalho foi a Teoria Cognitiva da Aprendizagem Multimídia, de Richard Mayer, apresentada por Carvalho (2002) em um artigo publicado na revista Portuguesa de Educação.

De acordo com a autora, um dos pressupostos da teoria consiste na avaliação do modo como estabelecemos a representação mental de forma coerente no interior do processamento cognitivo durante a aprendizagem. A atividade perpassa, segundo, ela, em "prestar a atenção, organizar a nova informação e integrá-la no conhecimento existente" (p. 259). Nessa perspectiva, Carvalho (2002) retoma os seis princípios elaborados por Mayer (2001) na tentativa de utilizá-los como um guia na criação de peças didáticas multimídias. São eles: o princípio multimídia, o princípio de proximidade espacial (quando imagens e palavras estão próximas em vez de afastadas), o princípio da proximidade temporal (quando imagens e palavras são apresentadas simultaneamente em vez de sucessivamente), o princípio da coerência (quando imagens, palavras e sons não relevantes para o assunto são excluídos), o princípio da modalidade (quando se utiliza animação e narração em vez de animação e texto escrito) e o princípio da redundância (quando se utiliza animação e narração em vez de animação, narração e texto).

A ideia de retomar ao pensamento de Mayer, destacado por Carvalho (2002), auxiliou Schneider e Ribeiro (2013) no encaminhamento de alguns questionamentos 
sobre os vídeos educativos que iriam ser analisados. A preocupação dos pesquisadores era responder às seguintes questões: qual é proporção da altura do texto em relação à imagem enquadrada que garante a legibilidade num dispositivo móvel? Qual o grau de zoom ou enquadramento era necessário para mostrar uma peça ou componente tecnológico de forma que o mesmo ainda mantivesse suas características reconhecidas? Qual o tamanho mínimo da tela de um computador para mostrar detalhes importantes? (p. 7).

\section{Análise:}

Conforme verificado pelos autores, as características de legibilidade na maioria dos vídeos avaliados estavam correlacionadas com o tamanho proporcional do texto em relação à altura da tela do computador, ou seja, dentro do limite adequado de legibilidade, no entanto, em alguns casos, os caracteres não apresentavam contraste suficiente, tornando-os ilegíveis. Em outros casos, os caracteres e fundo apresentavam contraste, mas a proporção era pequena e o texto permanecia ilegível.

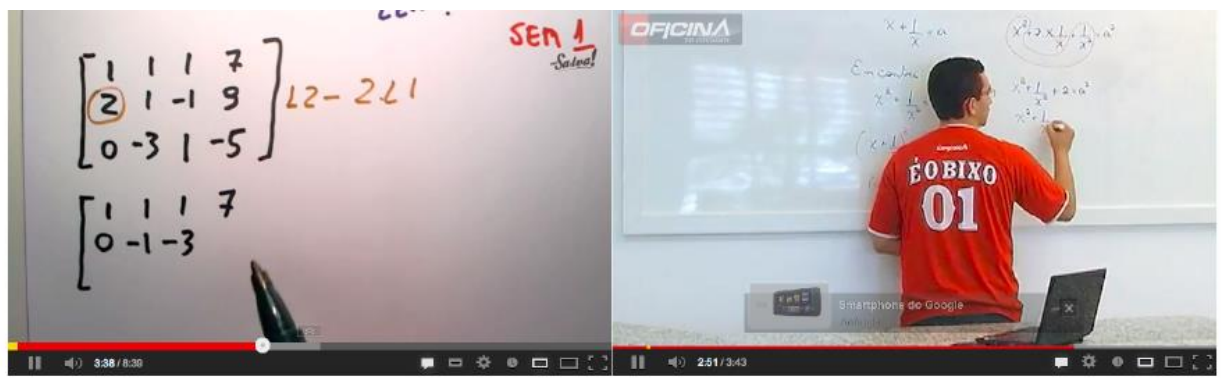

Figura 1: Imagens de alguns vídeos analisados pelo Núcleo de Produção e Tecnologia Educacional (NPTE).

Em relação ao enquadramento de planos, como destacado na figura acima, em alguns vídeos, foram verificados técnicas inadequadas de filmagem, como o uso do Plano Americano (PA) durante a captação de imagens, quando o ideal para destacar caracteres alfanuméricos seria a utilização do Plano Médio Fechado (PMF), como ocorre no telejornalismo para marcar um ponto importante da notícia. 


\section{Vídeos caseiros produzidos pelo Núcleo de Educação a Distância da Universidade Federal do Maranhão (NEAD)}

Para compor esse estudo, e com base nas considerações de Carvalho (2002) e Schneider e Ribeiro (2013), também foram considerados sete vídeos caseiros produzidos, em 2013, por professores e tutores do curso de Licenciatura a Distância de Matemática do Núcleo de Educação a Distância da UFMA e disponibilizados no AVA. Os vídeos surgiram da demanda de alguns alunos dos polos do interior sobre temáticas relacionadas a cálculo e continuidade por exemplo. A produção ocorreu no próprio Campus da UFMA, em São Luís-MA por alunos, docentes e tutores, por meio de smarthphones e tablets pessoais. A edição e postagem do material no AVA ocorreu, em grande parte, no mesmo dia da gravação, por um computador disponibilizado no NEAD - UFMA e era realizado pelos próprios professores e alunos.

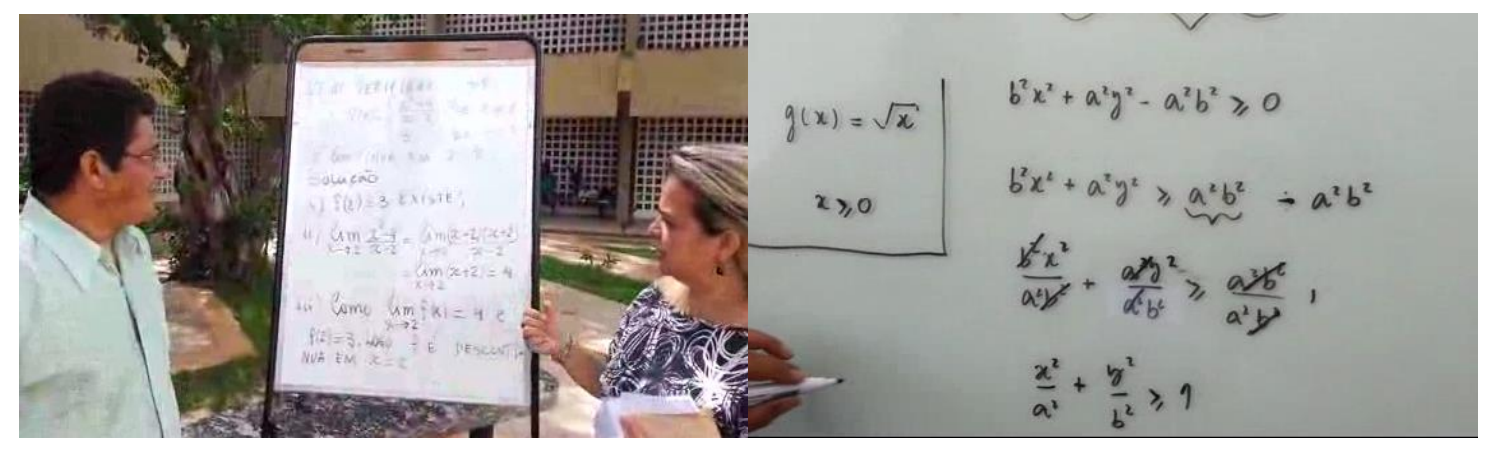

Figura 2: Imagens de alguns vídeos analisados pelo Núcleo de Educação a Distância da Universidade Federal do Maranhão.

\section{Análise:}

Nessa amostra, pode-se também verificar o uso dos dois planos (PA, PMF) na maioria dos vídeos. Na primeira imagem da Figura 2, observa-se que o PMF destaca os professores, no entanto, o conteúdo do material fica prejudicado. Em todos os vídeos, é possível identificar o uso efeito do zoom, para aproximar ou distanciar as imagens. No entanto, esse recurso foi feito de forma inadequada causando prejuízo à imagem (desfocada), tornando-a indefinida e prejudicando o conteúdo didático. Sobre as características de legibilidade, na maioria dos vídeos avaliados, após o uso do efeito do 
zoom na imagem (quando não havia perda de foco), o tamanho do texto correspondia ao limite adequado de legibilidade. No entanto, os caracteres, em sua maioria, não apresentaram contraste suficiente, tornando-os pouco legíveis. O áudio dos vídeos avaliados foi, em sua maioria, prejudicado, já que houve interferência e excesso de ruído dos ambientes externos sem o uso de um microfone, dificultando, assim, o entendimento das informações veiculadas pelos professores e tutores.

\section{Considerações Finais}

As análises do Núcleo de Produção e Tecnologia Educacional (NPTE) do Instituto Federal de Educação, Ciência e Tecnologia Sul-rio-grandense (IFSUL) e dos vídeos gravados por alunos e tutores do curso de Licenciatura em Matemática a Distância pelo NEAD nos chamam atenção quanto à importância no planejamento e elaboração dos materiais audiovisuais (conhecimento sobre o uso adequado do tamanho, das cores e dos contrastes de legendas, áudio, enquadramentos e zoom) produzidos tanto por profissionais da área de comunicação quanto pelos da educação e informação proporcionada pelo uso dos dispositivos móveis. É preciso avaliar quando há possibilidade de explorar os inúmeros recursos oferecidos pela tecnologia e como fazer para obter êxito, resultando em uma aprendizagem dinâmica e contextualizada, já que, como aponta Moran (2012), "as tecnologias móveis, quando chegam às mãos de alunos e professores, trazem desafios imensos de como organizar esses processos de forma interessante, atraente e eficiente, dentro e fora da sala de aula". O futuro da EAD com a implantação do ambiente digital no currículo presencial nos provoca , cada vez mais, a aprofundar o conhecimento com esse intercâmbio de propostas promovidas por outras Instituições de Ensino e Pesquisa na construção de modelos de aprendizagem cada vez mais arrojados, testados e aceitos por todos os envolvidos nesse processo: técnicos e pesquisadores da informação e comunicação, alunos e professores. 


\section{Notas}

$1 \mathrm{O}$ artigo foi divulgado no $X$ Congresso Brasileiro de Ensino Superior a Distância Belém/PA, 11 - 13 de junho de 2013 - UNIREDE.

2 Segundo o autor, estudos realizados pelo IPEA, com base em elementos disponíveis na época, entre os quais estão as edições de jornais editados, como por exemplo o Jornal do Brasil, mostram que, pouco antes de 1900, já existiam anúncios em jornais de circulação no Rio de Janeiro oferecendo cursos profissionalizantes por correspondência.

3 Moraes e Nogueira (s/d) destacam que, conforme Lei no. 9.394/96, os antigos primeiros e segundos graus são correspondentes, respectivamente, ao ensino fundamental e ensino médio.

${ }^{4}$ Sobre o histórico e expansão da internet no Brasil, Takahashi (2000) relata que uma primeira versão desse serviço com pontos em 21 estados foi implantada pela Rede Nacional de Pesquisa (RNP), de 1991 a 1993, com velocidade baixa. A partir de junho de 1995, uma decisão do Governo Federal definiu regras gerais para disponibilização da internet em território nacional.

\section{Referências Bibliográficas}

Carvalho, A. A. A. (2002). Multimédia: um conceito em evolução. Revista Portuguesa de Educação, 2002. Acesso em 27 de junho de 2013, disponível em: http://repositorium.sdum.uminho.pt/bitstream/1822/489/1/AnaAmelia.pdf

Dornelles, R. (2001). A utilização da tecnologias da internet na educação a distância: o caso de uma disciplina de graduação da Escola de Administração da Universidade Federal do Rio Grande do Sul (Mestrado em Administração). Universidade Federal do Rio Grande do Sul, UFRGS.

Gouvêa, Guaracira; Oliveira, Carmem Irene. (2006). Educação a distância na formação de professores: viabilidade, potencialidades e limites. Rio de Janeiro: Vieira \& 
Lent.

Jenkins, Henry. (2009). Cultura da Convergência. Editora Aleph, 2009.

Montano, Carlos; Duriguetto, Maria Lúcia. (2011). Estado, classe e movimento social. 3 ed. São Paulo: Cortez.

MORAES, Raquel de Alemira; NOGUEIRA, Danielle Xabregas. Educação a distância no Brasil: uma análise histórica das políticas educacionais brasileiras. Acesso em 21 de junho de 2013, disponível em: http://www.histedbr.fae.unicamp.br/acer histedbr/seminario/seminario8/ files/ ZjWcalx9.doc

Moran. Jose Manuel, s/d. Tablets para todos conseguirão mudar a escola? Acesso em 27 de junho de 2013, disponível em http://www.eca.usp.br/prof/moran/index9.html

Passsinho, S. R. (2007). Educação "Fora do Ar": Uma análise da TVE Maranhense nas reminiscências dos seus participantes. In: $5^{\circ}$ Encontro de educação e tecnologias de informação e comunicação, Anais... Rio de Janeiro. Acesso em 20 de março de 2014, disponível em: http://etic2008.files.wordpress.com/2008/11/unesasandrapassinho.pdf

SEPAC. (Serviço à Pastoral de Comunicação). (2007). Vídeo: da emoção à razão. São Paulo: Paulinas. (Coleção Pastoral da Comunicação: teoria e prática. Séries manuais.

Schneider, Catiúcia Klug, RIBEIRO, Luis Otoni Meireles. A produção do video para internet na Educação a Distância. IN: X Congresso Brasileiro de Ensino Superior a Distância Belém/PA, 11 - 13 de junho de 2013 - UNIREDE

SORJ. Bernard. Brasil@povo.com. (2003). A luta contra a desigualdade na Sociedade da Informação. Rio de Janeiro: Jorge Zahar. Ed. Brasília, DF: UNESCO.

TAKAHASHI, Tadao (Org.). (2000). Sociedade da Informação no Brasil: Livro Verde. Brasília: Ministério da Ciência e Tecnologia. 